\title{
Influence of solar radiation absorbed by phytoplankton on the thermal structure and circulation of the tropical Atlantic Ocean
}

Robert Frouin, Kyozo Ueyoshi, Milton Kampel

Robert Frouin, Kyozo Ueyoshi, Milton Kampel, "Influence of solar radiation absorbed by phytoplankton on the thermal structure and circulation of the tropical Atlantic Ocean," Proc. SPIE 6680, Coastal Ocean Remote Sensing, 668015 (5 October 2007); doi: 10.1117/12.738969

SPIE Event: Optical Engineering + Applications, 2007, San Diego, California, United States 


\title{
Influence of Solar Radiation Absorbed by Phytoplankton on the Thermal Structure and Circulation of the Tropical Atlantic Ocean
}

\author{
Robert Frouin $^{\mathrm{a} *}$, Kyozo Ueyoshi ${ }^{\mathrm{a}}$, Milton Kampel ${ }^{\mathrm{b}}$ \\ ${ }^{a}$ Climate Research Division, Mail Code 0224, Scripps Institution of Oceanography, \\ 8810 Shellback Way, La Jolla, California 92037, USA \\ bDivisão de Sensoriamento Remoto, Instituto Nacional de Pesquisas Espaciais, \\ Av. dos Astronautas, 1758 São José dos Campos, SP, 12227-010, Brazil
}

\begin{abstract}
Numerical experiments conducted with an ocean general ocean circulation model reveal the potential influence of solar radiation absorbed by phytoplankton on the thermal structure and currents of the Tropical Atlantic Ocean. In the model, solar radiation penetration is parameterized explicitly as a function of chlorophyll-a concentration, the major variable affecting water turbidity in the open ocean. Two types of runs are performed, a clear water (control) run with a constant minimum chlorophyll-a concentration of $0.02 \mathrm{mgm}^{-3}$, and a turbid water (chlorophyll) run with space- and time-varying chlorophyll-a concentration from satellite data. The difference between results from the two runs yields the biological effects. In the chlorophyll run, nutrients and biology production are implicitly taken into account, even though biogeochemical processes are not explicitly included, since phytoplankton distribution, prescribed from observations, is the result of those processes. Due to phytoplankton-radiation forcing, the surface temperature is higher by $1-2 \mathrm{~K}$ on average annually in the region of the North Equatorial current, the Northern part of the South Equatorial current, and the Caribbean system, and by 3-4 K in the region of the Guinea current. In this region, upwelling is reduced, and heat trapped in the surface layers by phytoplankton is not easily removed. The surface temperature is lower by $1 \mathrm{~K}$ in the Northern region of the Benguela current, due to increased upwelling. At depth, the equatorial Atlantic is generally cooler, as well as the eastern part of the tropical basin (excluding the region of the sub-tropical gyres). The North and South equatorial currents, as well as the Equatorial undercurrent, are enhanced by as much as 3-4 $\mathrm{cms}^{-1}$, and the circulation of the subtropical gyres is increased. Pole-ward heat transport is slightly reduced North of $35^{\circ} \mathrm{N}$, suggesting that phytoplankton, by increasing the horizontal return flow in the subtropical region, may exert a cooling influence on higher latitude regions. The findings indicate that biology-induced buoyancy plays a significant role, in an indirect if not direct way, in the variability of the Tropical Atlantic Ocean, with consequences on atmospheric circulation and climate.
\end{abstract}

Keywords: Ocean circulation, numerical modeling, remote sensing, Tropical Atlantic, ocean color, phytoplankton

\section{INTRODUCTION}

Phytoplankton, by absorbing solar radiation and redistributing heat in the vertical, may affect the thermal structure of the upper ocean and induce dynamical changes. This was early pointed out by Denman et al. ${ }^{1}$, who showed that allowing solar penetration below the mixed layer could increase mixed layer depth by $70 \%$. Later Charlock ${ }^{2}$, employing a one-dimensional climate model with energy balance, noted that sea surface temperature (SST)

*E-mail: rfrouin@ucsd.edu; Phone: 1858534 6243; Fax: 18585348561

Coastal Ocean Remote Sensing, edited by Robert J. Frouin, ZhongPing Lee, Proc. of SPIE Vol. 6680, 668015, (2007) · 0277-786X/07/\$18 · doi: 10.1117/12.738969

Proc. of SPIE Vol. $6680668015-1$ 
increased by $1-2 \mathrm{~K}$ when water was more turbid. Woods et al. ${ }^{3}$ emphasized the need for accurate calculation of the vertical profile of solar heating to meet the requirements of climate prediction. They showed that the rate of solar heating below the mixed layer depends more on water turbidity than cloud cover. Martin ${ }^{4}$, using various mixed-layer models, reported SST changes of several degrees K at Ocean Weather Stations Bravo and November due to water turbidity. Simonot et al. ${ }^{5}$, coupling a mixed-layer model to a primary production model, found that the seasonal cycle of phytoplankton at Ocean Weather Station Romeo had a significant impact on simulated SST. Sathyendranath et al. ${ }^{6}$, using the Kraus-Turner mixed-layer model, calculated a biological heating of $4 \mathrm{~K}$ per month during AugustSeptember in the Arabian Sea.

Most ocean general circulation models (OGCMs) treat solar radiation in the same way for the entire ocean, by either specifying a global attenuation depth or absorbing all solar radiation within the mixed layer. Schneider and $\mathrm{Zhu}^{7}$ compared these two methods and determined that a global attenuation depth yielded a more realistic SST seasonal cycle in the equatorial Pacific. Previously, Lewis et al. ${ }^{8}$ had argued, based on in situ measurements of heat fluxes, that ocean transparency in the western Pacific Ocean might explain SST overestimation by OGCMs which assume that all solar radiation is absorbed at the surface. Using a global attenuation depth, however, is not realistic, since phytoplankton biomass, therefore light penetration, is variable in space and time.

Recently, using satellite ocean-color imagery, space- and time-varying absorption of solar radiation by phytoplankton was incorporated in OGCMs. Nakamoto et al. ${ }^{9,10}$ and Frouin et al. ${ }^{11}$ compared simulations with either spatially- and seasonally-varying absorption or a constant attenuation depth of $23 \mathrm{~m}$ (clearest waters) in the Arabian Sea, Equatorial Pacific, and global ocean, respectively. They found a large-scale amplification of the SST seasonal cycle due to phytoplankton, by typically $20 \%$. The amplification reached $1.5 \mathrm{~K}$ in some regions where mixed layer was shallow. The simulations also revealed systematically lower SST in the eastern Equatorial Pacific. This was also obtained by Manizza et al. ${ }^{12}$ in model runs that considered not only the impact of phytoplankton on ocean physics, but also the response of phytoplankton to the modified nutrient supply and light availability. Murtugudde et al. ${ }^{13}$ determined the spatial pattern of attenuation depth in a tropical ocean model and compared the results with those obtained using a constant attenuation depth of $17 \mathrm{~m}$, the global mean value. They argued that the problem of a colder than observed cold tongue in the eastern Equatorial Pacific is remedied by using an accurate solar heating parameterization. Subrahmanyam et al. ${ }^{14}$ reported large seasonal variability in the meridional overturning circulation and heat transport of the Indian Ocean. In all these studies, the heating changes due to phytoplankton resulted in dynamical changes, such as anomalous currents and upwelling. Kara et al. ${ }^{15}$, on the other hand, indicated that using a spatially and temporally varying instead of constant attenuation coefficient for solar radiation had low impact overall on OGCM predictions of SST times series at moored-buoy locations in different regions of the global ocean, but pointed out that using it improved predictions at low latitudes and can have a substantial impact locally.

The heating changes resulting from absorption of solar radiation by phytoplankton can in turn influence the atmosphere, which responds to the SST. The atmospheric response has been investigated with the NCAR Community Climate Model, version 3 (CCM-3) by Shell et al. ${ }^{16,17}$, who used SST anomalies generated as part of Nakamoto et al. ${ }^{9,10}$. The main effect of incorporating the perturbed SST due to phytoplankton is an amplification of the seasonal cycle in the lowest layer atmospheric temperature by about $0.3 \mathrm{~K}$, similar to the amplification found in the SST itself. The warming in summer is marginally larger than the cooling in winter, so that air temperature in the phytoplankton run is about $0.05 \mathrm{~K}$ warmer overall than in the control run. The air temperature anomalies over the ocean closely follow the SST anomalies, but there are also significant temperature changes over land (remote effects). In response to the amplification of the seasonal cycle in the phytoplankton run, precipitation in the intertropical convergence zone is enhanced in the summer hemisphere. Timmerman and $\mathrm{Jin}^{18}$ and Marzeion et al. ${ }^{19}$, using coupled ocean-atmosphere models, found that effects of phytoplankton-radiation forcing in the Tropical Pacific might be enhanced via interactions with the atmosphere. Potential feedbacks in inter-decadal climate variation are 
summarized in Miller et al. ${ }^{20}$. Further investigation is needed, however, to precise the mechanisms at work and quantify effects that can be compared with observations.

In this context, the goal of the study is to explore further the role of biology, more precisely absorption of solar radiation by phytoplankton, in ocean dynamics, focusing on the Tropical Atlantic Ocean. Our starting hypothesis, based on previous numerical simulations, is that the presence of phytoplankton in the upper oceanic layers, by modifying buoyancy, plays a significant role, in an indirect if not direct way, in the variability of the Tropical Atlantic Ocean on seasonal to inter-annual time scales. Specifically, the study aims at quantifying the effect of space- and time-varying phytoplankton on currents and thermal structure and at identifying the mechanisms, local or remote, by which they are maintained or modified. The objective is also to draw conclusions on whether biology forcing should be included explicitly in the modeling of seasonal and inter-annual variability of the Tropical Atlantic Ocean.

\section{NUMERICAL EXPERIMENTS}

The approach is basically to run an OGCM with and without explicit parameterization of solar radiation absorption by phytoplankton. The difference between results of the two types of runs yields biological effects. Pigment concentration is specified at each time step from satellite data, not predicted. The effects of nutrients and biological production are implicitly taken into account, even though biogeochemical processes are not included explicitly, since phytoplankton distribution is the result of those processes. Of course, by prescribing phytoplankton abundance our approach does not have any predictive capability to assess feedbacks on ocean biology. This important aspect is beyond the scope of this sensitivity study, which essentially aims at quantifying effects of realistic phytoplanktonradiation forcing.

The OGCM is a version of the MITGCMUV, a primitive equation model developed at MIT (Marshall et al. ${ }^{21,22}$ ). MITGCMUV has been used successfully in a variety of configurations including small-scale convection and globalscale ocean simulations. Some of the experiments are summarized in Marshall et al. ${ }^{22}$. The model has $23 \mathrm{z}$ coordinate vertical levels with the top eight layers set to $10 \mathrm{~m}, 10 \mathrm{~m}, 15 \mathrm{~m}, 20 \mathrm{~m}, 25 \mathrm{~m}, 35 \mathrm{~m}, 50 \mathrm{~m}$, and $75 \mathrm{~m}$. The horizontal domain covers latitudes from -80 to 80 degrees, with a uniform grid resolution of 1 degree in both latitude and longitude directions. The model incorporates a KPP mixing scheme along with Redi-Gent-McWilliams sub-grid mixing schemes. Ocean bottom topography is based on the 2-minute resolution global sea floor topography derived by Smith et al. ${ }^{23}$.

External forcing at the ocean surface is accomplished using NCEP re-analysis data sets for 1948-2001. They consist of twice-daily wind stress components, daily evaporation minus precipitation, daily short wave heat flux, and daily total heat flux excluding the short wave heat flux (i.e., long wave and turbulent components). The temperature in the top layer of the model is restored towards Reynolds monthly mean temperature with a relaxation period of one month, and sea surface salinity is nudged to Levitus monthly climatology with the same relaxation period. The temperature and salinity in the lower layers are dynamically prognosticated without such a constraint.

Solar radiation penetration is parameterized according to Morel and Antoine ${ }^{24}$. This allows computation of the heating rate profile as a function of surface phytoplankton pigment concentration, as determined from satellite ocean-color imagery. The pigment concentration is assumed constant vertically. This treatment is sufficient, since at depth the residual radiant energy is low. (This assumption will be further discussed in Section 3.) Figure 1 shows, for the visible part of the solar spectrum (wavelengths of less than $0.75 \mu \mathrm{m}$ ), solar transmittance as a function of depth for various pigment concentrations in the range $0-20 \mathrm{mgm}^{-3}$. Paulson and Simpson ${ }^{25}$, s values for clear waters are also displayed. The transmittance profiles are strongly affected by the presence of phytoplankton. About $30 \%$ of 
the visible light is transmitted below $20 \mathrm{~m}$ in the case of pure seawater, but only $0.01 \%$ when the pigment concentration is $20 \mathrm{mgm}^{-3}$. Paulson and Simpson ${ }^{25}$, s values correspond roughly to Morel and Antoine ${ }^{24}$, s values for a pigment concentration of $0.02 \mathrm{mgm}^{-3}$, although significant differences exist below $30 \mathrm{~m}$, i.e., a higher transmittance with Paulson and Simpson ${ }^{25}$ 's formula.

Two types of runs were performed, a clear water control run with a minimum pigment concentration of $0.02 \mathrm{mgm}^{-3}$ (C002) and a turbid water run with space and type varying chlorophyll-a concentration derived from satellite data (CHL). In both runs the Morel and Antoine ${ }^{24}$ parameterization was used, unlike in the numerical experiments of Nakamoto et al. ${ }^{9,10}$, who used the Paulson and Simpson ${ }^{25}$ formula in the control run and the Morel and Antoine ${ }^{24}$ parameterization in the chlorophyll run. This procedure eliminates uncertainties associated with crossover of vertical heating rate profiles. Furthermore, using the same scheme in both types of experiments guarantees that the heating rate due to solar irradiance at a given depth, location, and time is always higher in CHL than in C002, making more straightforward the analysis of the biology-induced ocean response. C002 was performed for 57 years from 1948 to 2004, starting with the ocean at rest, and CHL from 1997 to 2004 with chlorophyll-a concentration obtained from POLDER and SeaWiFS data (interpolated as necessary). The restart conditions at the model start time of January 01, 1997 in CHL were specified using the model status at the end of 1996 obtained in C002. Because of the timedependent nature of the NCEP re-analysis data set, the upper ocean is not in a cyclo-stationary state at the start of CHL. The mixed layer depth of the z-coordinate MITGCMUV is not resolved explicitly, but diagnosed.

\section{RESULTS AND DISCUSSION}

The output of CHL is compared with the output of C002 for annually averaged values of temperature, mixed layer depth, and currents. The comparison is made for 2003, a relatively normal year, but the results are similar for other years. Seasonal and inter-annual variability is illustrated at a specific location. The results are presented in terms of differences between CHL and CRTL values, which thus give the effect of space and time varying, biology-induced ocean transparency, hence solar radiation penetration, on Tropical Atlantic circulation and thermal structure, with respect to the clearest water case.

Figure 2 displays the annual mean chlorophyll-a concentration in the study area for year 2003. Variability is large, with low concentration in the subtropical gyres and relatively high concentration in the upwelling systems off West Africa and at the Equator and in the regions influenced by the Rio de La Plata and Amazon rivers. The e-folding light attenuation depth changes from about 3 to $20 \mathrm{~m}$, in some regions over relatively short distances, affecting the spatial gradients of heating rate. As a consequence, surface temperature is modified substantially (Figure 3), with values higher by 1-2 K on average annually in the region of the North Equatorial current, the Northern part of the South Equatorial current, the Brazil current, and the Caribbean system, and by 3-4 K in the region of the Guinea current. Values are not higher everywhere, however. The surface temperature is lower by $1 \mathrm{~K}$ in the Northern region of the Benguela current, and there is only marginal change in the Eastern equatorial region. This suggests that the change in surface temperature may not be governed only by local buoyancy, but also by remote processes in which advection should play a role. In other words, if phytoplankton-radiation forcing tends to reduce the mixed layer almost everywhere (Figure 4) and therefore to trap more heat at the surface, the spatial changes of heating rate, by inducing density anomalies and currents, may contribute to the final result, even dominate.

The situation can be further explained by examining the zonal velocity differences in the surface layer (Figure 5 , top) and sub-surface, namely $60 \mathrm{~m}$ (Figure 5, bottom). In the surface layer, due to phytoplankton-radiation forcing the South Equatorial system, the Guiana current, and the Caribbean system are enhanced but up to $4 \mathrm{cms}^{-1}$ (about 10 $15 \%)$. As a consequence, upwelling in the zone of divergence of the South Equatorial system is increased and more heat is transferred to the Caribbean region. The Benguela current is also enhanced, as well as the circulation of the 
sub-tropical gyres. Due to the stronger Benguela current, upwelling is increased in that region, resulting in cooler waters at the surface. The Guinea and Angola currents, however, are weaker, which contributes to reduce upwelling and therefore help to trap heat at the surface. At $60 \mathrm{~m}$ depth, the eastward circulation is enhanced in the equatorial region, especially in the eastern part of the basin, where current speed increases by up to $25 \%$ (Figure $5 \mathrm{~b}$ ). In the subtropical North Atlantic, phytoplankton-radiation forcing generates a southward current that joins the eastward equatorial flow. The equatorial undercurrent is broadened and strengthened in its upper part and weakened in its lower part (Figure 7). The chlorophyll effects on temperature are not confined to the surface, but are felt at depth. In the North Atlantic, temperature is lower by up to $3 \mathrm{~K}$ at $60 \mathrm{~m} \mathrm{depth}$, and changes are still significant at $200 \mathrm{~m}$ (Figure 6).

The seasonal variability in temperature and currents is affected by biology forcing, as illustrated in Figure 8 , which displays time series of vertical temperature and zonal velocity at $2^{\circ} \mathrm{N}$ and $10^{\circ} \mathrm{W}$, i.e., in the Northern part of the South Equatorial current. If surface temperature is higher during all year, the amplitude of the seasonal cycle of temperature is increased (Figure 8a). Stability of the vertical column is strengthened with a warmer mixed layer and cooler water below. Contrary to temperature, the zonal current exhibits reduced variability during the year in the presence of phytoplankton-radiation forcing (Figure 8b). Inter-annual variability of temperature and zonal current is not negligible, but no single year stands out during 1997-2004.

Due to phytoplankton-radiation forcing, the meridional circulation of the Atlantic Ocean, which moves warm waters from the equator and tropics to high latitude regions, is increased in the upper layers (above $50 \mathrm{~m}$ ) and decreased below $50 \mathrm{~m}$ between $30 \mathrm{~S}$ and $30 \mathrm{~N}$ (Figure 9). The increase is largest at about $20 \mathrm{~m}$ and 5 degrees from the equator (1 Sv), and the decrease is largest at about $90 \mathrm{~m}$ and 10 degrees from the equator $(1.5 \mathrm{~Sv}$ in the Southern hemisphere and $0.8 \mathrm{~Sv}$ in the Northern hemisphere). These changes are reflected in the pole-ward heat transport, which is slightly increased from the equator to $35^{\circ} \mathrm{N}$, and from the Equator to about $20^{\circ} \mathrm{S}$ (Figure 10 ). Above $35^{\circ} \mathrm{N}$, however, heat transport is decreased. Thus phytoplankton acts at reducing the transport of heat from the tropics to higher latitudes in the North Atlantic. This is also evidenced in the increase of subtropical gyre circulation, i.e., in the return flow (subtropical recirculation). Global ocean-atmosphere computer models have predicted such an effect due to global warming, for which some evidence has been recently provided by Bryden et al. ${ }^{26}$ (see also Quadfasel ${ }^{27}$ ). In a similar way, phytoplankton, by interacting with solar radiation and increasing the return flow, tends to contribute to a cooler climate in North Atlantic countries, especially Europe.

\section{ACKNOWLEDGMENTS}

This work was supported by the National Science Foundation, by the National Aeronautics and Space Administration, by the Instituto Nacional de Pesquisas Espaciais, and by the Scripps Institution of Oceanography.

\section{REFERENCES}

1. Denman, K. L., A time-dependent model of the upper ocean, J. Phys.Oceanogr., 3, 173-184, 1973.

2. Charlock, T. P., Mid-latitude model analysis of solar radiation, the upper layers of the sea, and climate, $J$. Geophys. Res., 87, 8923-8930, 1982.

3. Woods, J. D., W. Barkman, and A. Horch, Solar heating of the oceans --diurnal, seasonal and meridional variation, Q. J. R. Meteorol. Soc., 110, 633-656, 1984.

4. Martin, P. J., Simulation of the mixed layer at OWS November and Papa with several models, J. Geophys. Res., 90, 903-916, 1985.

5. Simonot, J.-Y., E. Dollinger, and H. Le Treut, Thermodynamic-biological-optical coupling in the oceanic mixed layer, J. Geophys. Res., 93, 8193-8202, 1988. 
6. Sathyadranath, S., A. D. Gouveia, S., R. Shetye, P. Ravindran, and T. Platt, Biological control of surface temperature in the Arabian Sea, Nature, 349, 54-56, 1991.

7. Schneider E. K., and Zhu Z. X., Sensitivity of the simulated annual cycle of sea surface temperature in the equatorial Pacific to sunlight penetration, J. Climate, 8, 1932-1950, 1998.

8. Lewis, M. A., M. E. Carr, G. C. Feldman, W. Esaias, and C. McClain, Influence of penetrating solar radiation on the heat budget of the equatorial Pacific Ocean, Nature, 347, 453-545, 1990.

9. Nakamoto, S., S. Prasana Kumar, J. M. Oberhuber, K. Muneyama, and R. Frouin, Chlorophyll control of sea surface temperature in the Arabian Sea in a mixed-layer isopycnal general circulation model, Geophys. Res. Lett.,27, 747-751, 2000.

10. Nakamoto, S., S. Prasanna Kumar, J.-M. Oberhuber, J. Ishizaka, K. Muneyama, and R. Frouin, Response of the equatorial Pacific to chlorophyll pigments in a mixed layer-isopycnal ocean general circulation model, Geophys. Res. Lett., 28, 2021-2024, 2001.

11. Frouin, R., S. Nakamoto, A. Paci, A. J. Miller, and S. F. Iacobellis, Biological modulation of sea surface temperature, Proceedings of the $5^{\text {th }}$ Pan-Ocean Remote Sensing Conference, Goa, India, 5-8 Dec. 2000, Vol. 2, 498-501, 2000.

12. Manizza, M., C. Le Quéré, A. J. Watson, and E. T. Buitenhuis, Bio-optical feedbacks among phytoplankton, upper ocean physics and sea-ice in a global model, J. Geophys. Lett., 32, L05603, doi:10.1029/2004GL020778, 2005.

13. Murtugudde R, J. Beauchamp, and A. Busalacchi, Effects of penetrative radiation on the upper tropical ocean circulation, J. Climate, 15, 470-486, 2002.

14. Subrahmanyam, B., K. Ueyoshi, and J. M. Morrison, Sensitivity of the Indian ocean circulation to phytoplankton forcing using an ocean model, Rem. Sen. Environ., in press, 2007.

15. Kara, A. B., H. E. Hurlburt, P. A. Rochford, and J. J. O’Brien, The impact of water turbidity on inter-annual sea surface temperature simulations in a layered global ocean model, J. Phys. Oceanogr., 34, 345-359, 2004.

16. Shell, K., R. Frouin, S. F. Iacobellis, and R. C. J. Somerville, Influence of Phytoplankton on Climate, Proceedings of the 12th AMS Symposium on "Global Change and Climate Variations", Jan. 2001, Albuquerque, New Mexico, 247-250, 2001.

17. Shell, K., R. Frouin, S. Nakamoto, and R. C. J. Somerville, Atmospheric response to solar radiation absorbed by phytoplankton, J. Geophys. Res., 108, doi: 10.1029/2003JD003440, 2003.

18. Timmermann, A., and F.-F. Jin, Phytoplankton influences on tropical climate, J. Geophys. Lett., 29, doi:10.1029/2002GL015434, 2002.

19. Marzeion, B., A. Timmerman, R. Murtugudde, and F.-F. Jin, Biophysical feedbacks in the Tropical Pacific, $J$. Climate, 18, 58-70, 2005.

20. Miller, A. J., M. A. Alexander, G. J. Boer, F. Chai, K. Denman, D. A. Erikson III, R. Frouin, A. Gabric, E. Laws, M. Lewis, Z. Liu, R. Murtugudde, S. Nakamoto, D. J. Neilson, J. R. Norris, C. Ohlmann, I. Perry, N.Schneider, K. Shell, and A. Timmermann, Potential feedbacks between Pacific ocean ecosystems and interdecadal climate variations, Bull. Am. Met. Soc., 617-633, 2003.

21. Marshall, J., C. Hill, L. Perelman, and A. Adcroft, Hydrostatic, quasi-hydrostatic, and non-hydrostatic ocean modeling, J. Geophys. Res., 102, 5733-5752, 1997.

22. Marshall, A. Adcroft, J., C. Hill, L. Perelman, and C. Heisey, A finite-volume, incompressible Navier-Stokes model for studies of the ocean in parallel computers, J. Geophys. Res., 102, 5753-5766, 1997.

23. Smith, W. H. F., and D. T. Sandwell, Global seafloor topography from satellite altimetry and ship depth soundings, Science, 277, 1956-1962, 1997.

24. Morel, A., and D. Antoine, Heating rate within the upper ocean in relation to its bio-optical state, J. Phys. Oceanogr., 24, 1652-1665, 1994.

25. Paulson, C. A., and J. J. Simpson, Irradiance measurements in the upper ocean, J. Phys. Oceanogr., 7, 952-956, 1977.

26. Bryden, H., H. R. Longworth, and S. A. Cunningham, Slowing of the Atlantic meridional overturning circulation at $25^{\circ} \mathrm{N}$, Nature, $\mathbf{4 3 8}, 655-657,2005$.

27. Quadfasel, D., The Atlantic heat conveyor slows, Nature, 439, 555-566, 2005. 


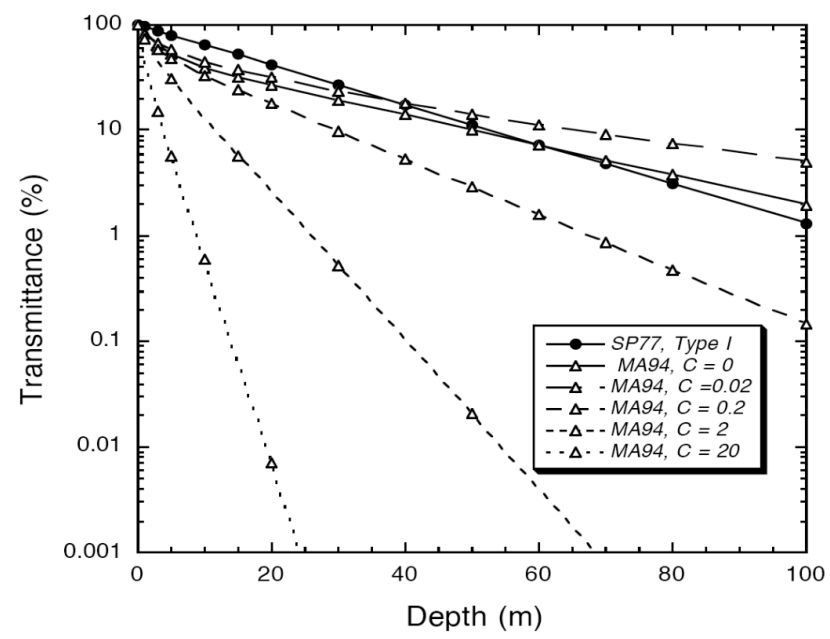

Figure 1. Sun light transmittance (wavelengths less than $0.75 \mu \mathrm{m}$ ) as a function of depth, for various values of chlorophyll-a concentration, $C$. The parameterization of Morel and Antoine (1994), MA94, is used in the computations. The profiles obtained with Paulson and Simpson's (1977) formula, SP77, are displayed for comparison.

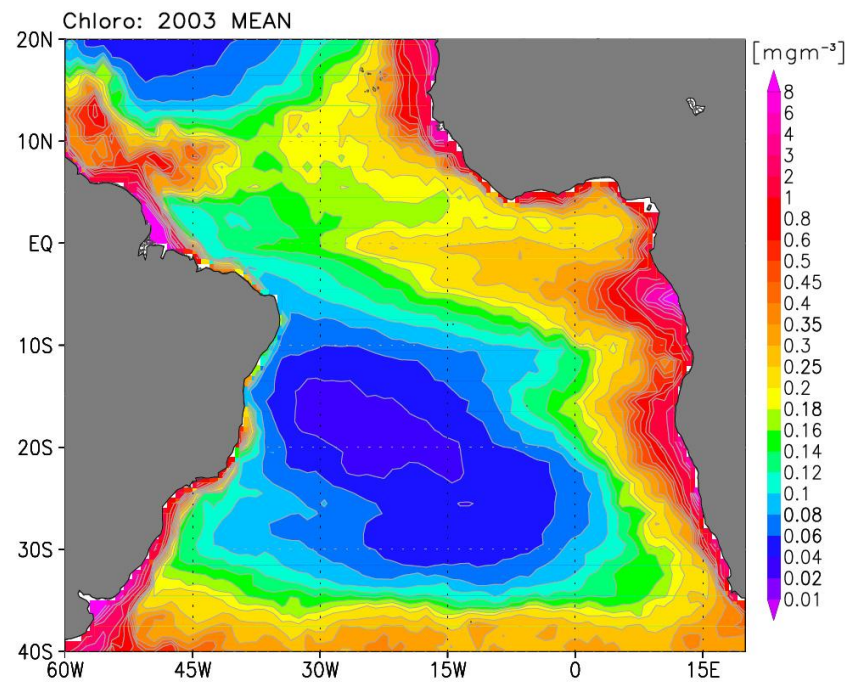

Figure 2. Annual mean near-surface chlorophyll-a concentration (year 2003) in the Atlantic as obtained from SeaWiFS data, showing the oligotrophic waters of the sub-tropical gyres, the productive waters of the upwelling systems off Northwest and Southwest Africa and at the Equator, and the chlorophyll-rich waters associated with the Rio de La Plata and the Amazon river effluents. 

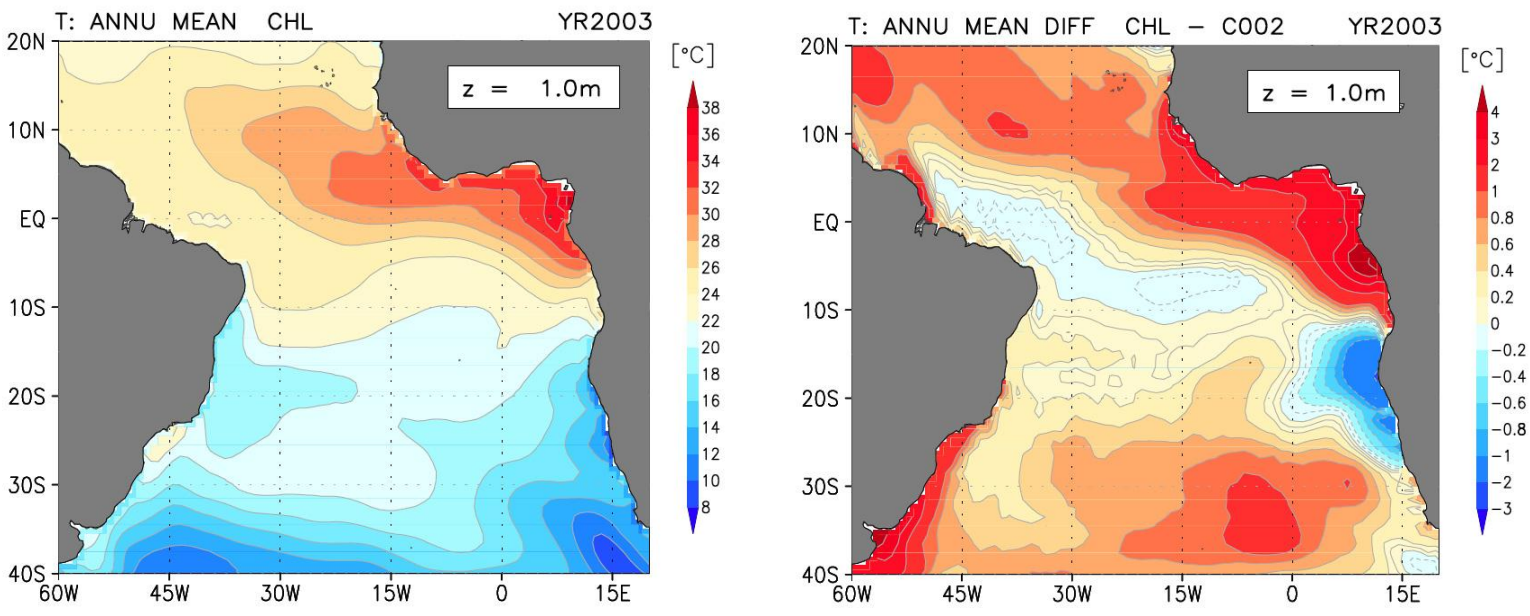

Figure 3. Mean annual surface temperature in the CHL run (top) and mean annual surface temperature difference between CHL and C002 runs (bottom). Year is 2003.
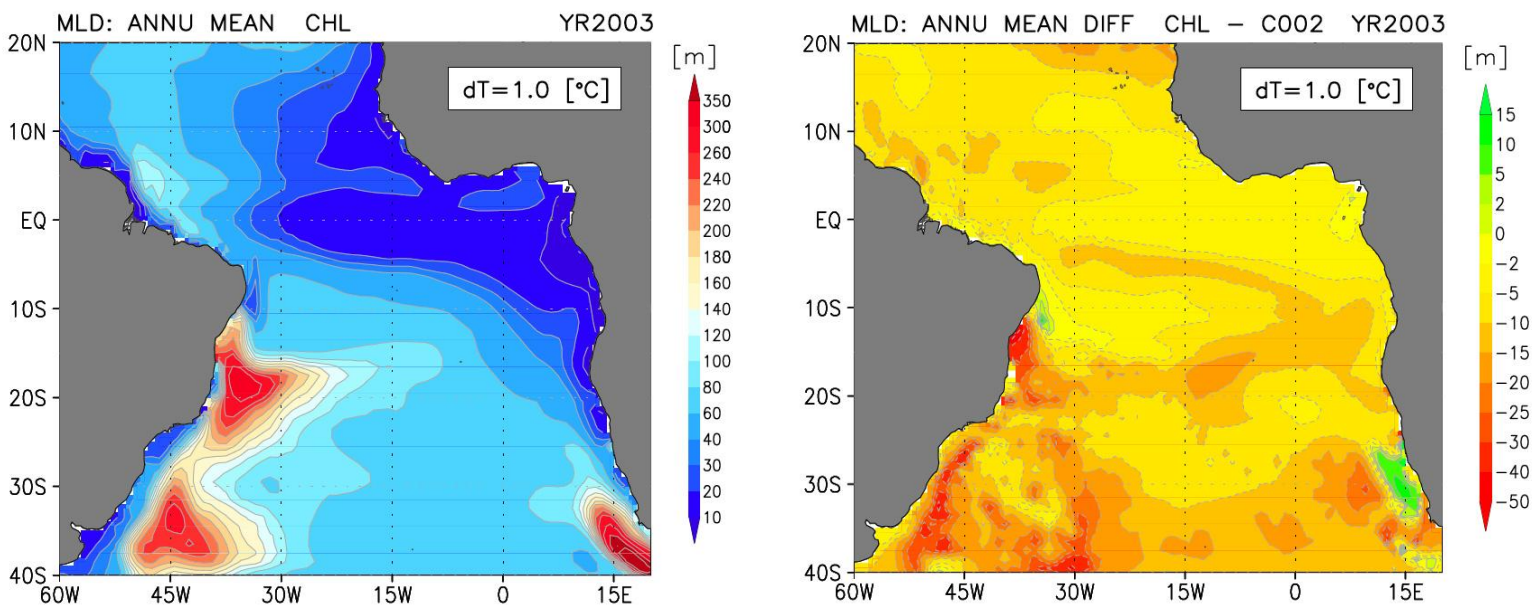

Figure 4. Mean annual mixed-layer depth in the CHL run (top) and mean annual mixed-layer depth difference between CHL and C002 runs (bottom). Year is 2003. 

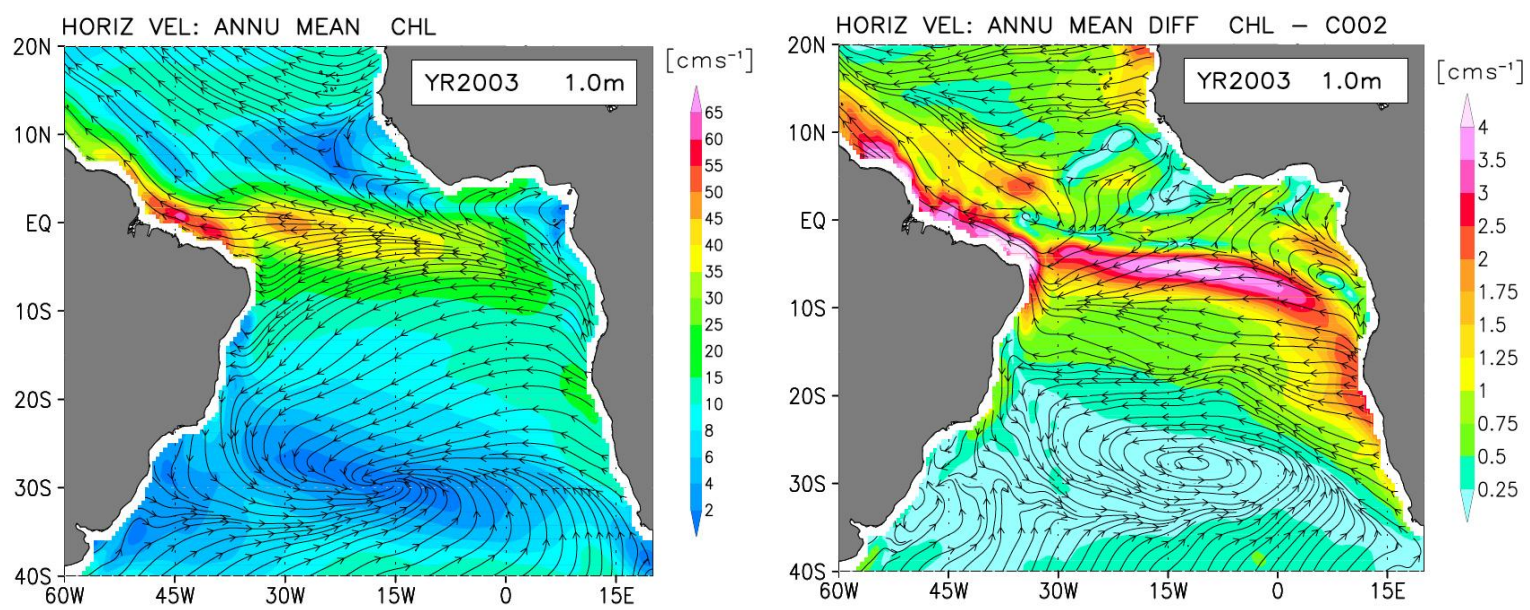

Figure 5a. Mean annual horizontal velocity in the CHL run (top) and mean annual horizontal velocity difference between CHL and C002 runs (bottom). Year is 2003, and depth is $1 \mathrm{~m}$.
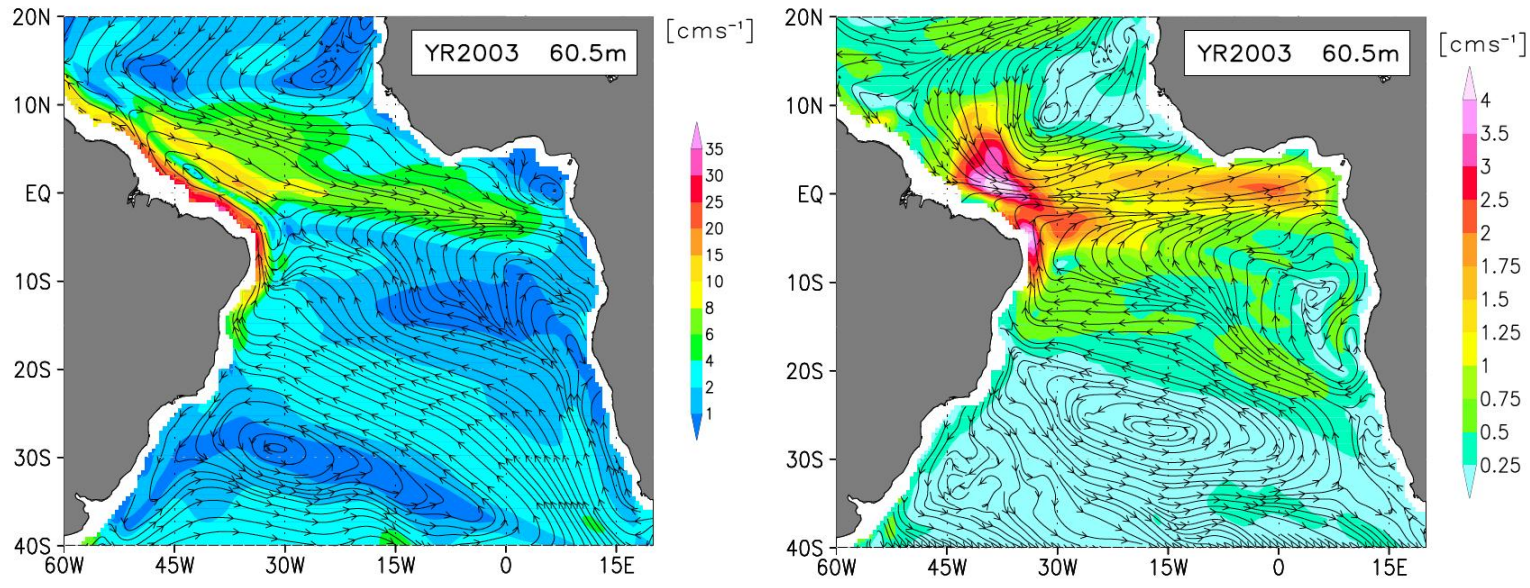

Figure 5b. Mean annual horizontal velocity in the CHL run (top) and mean annual horizontal velocity difference between CHL and C002 runs (bottom). Year is 2003, and depth is $60 \mathrm{~m}$. 

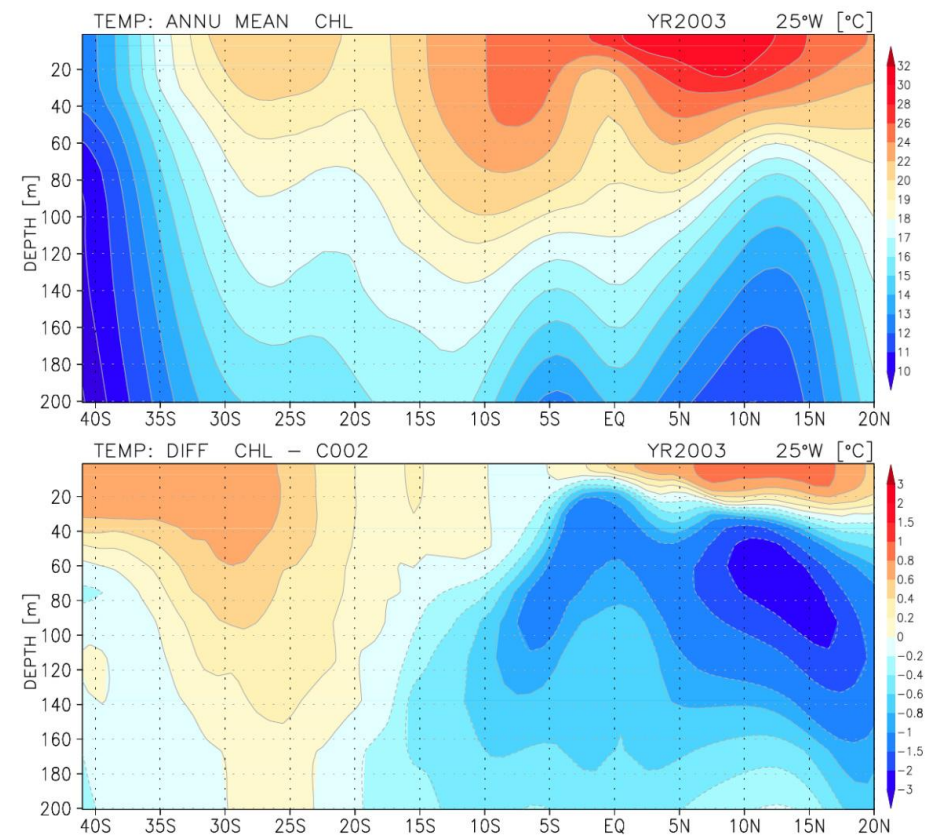

Figure 6. Vertical temperature cross-section between $40^{\circ} \mathrm{S}$ and $20^{\circ} \mathrm{N}$ and along $25^{\circ} \mathrm{W}$ : Top: Annual mean temperature (CHL run); Bottom: Annual mean temperature difference (CHL - C002 runs).
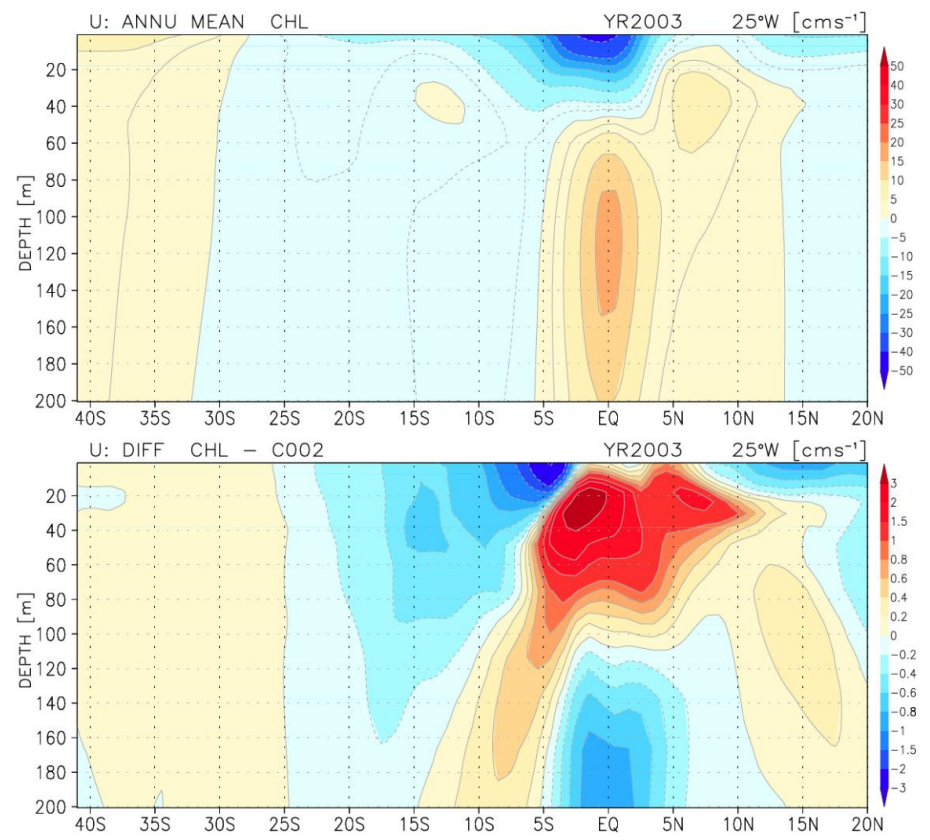

Figure 7. Zonal velocity cross-section along $25^{\circ} \mathrm{W}$ : Top: Annual mean velocity (CHL run); Bottom: Annual mean velocity difference (CHL-C002 runs). 

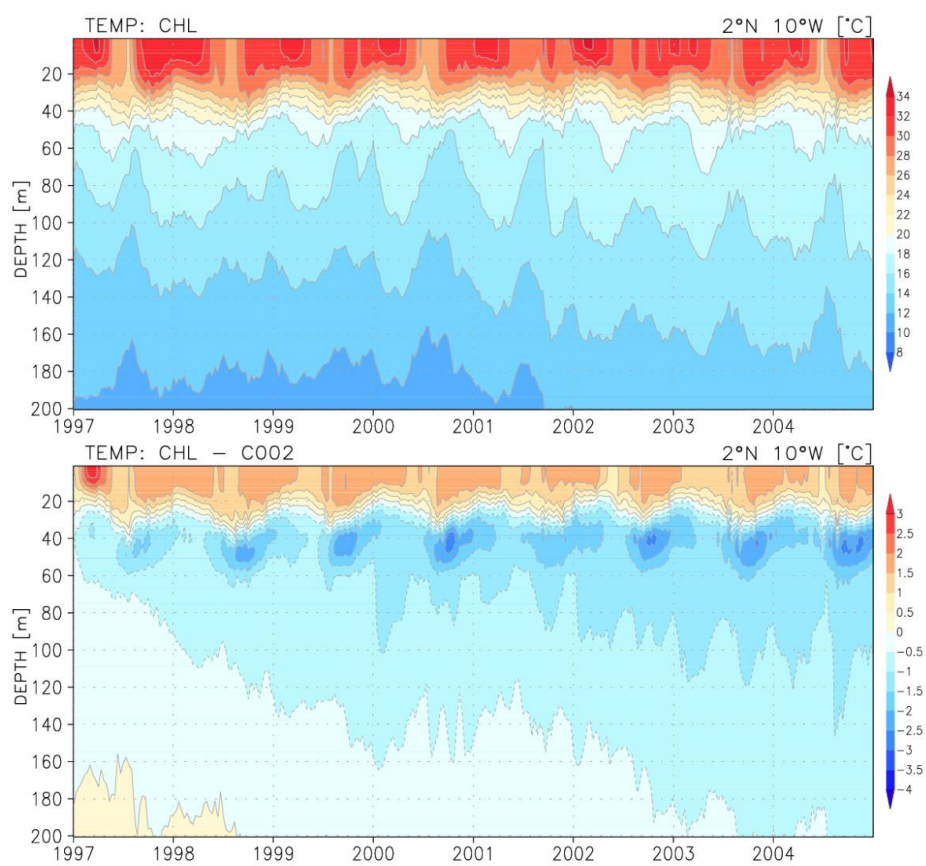

Figure 8a. Time series of vertical temperature profile at $2^{\circ} \mathrm{N}$ and $10^{\circ} \mathrm{W}$ : Top: CHL run; Bottom: Difference between CHL and C002 runs.
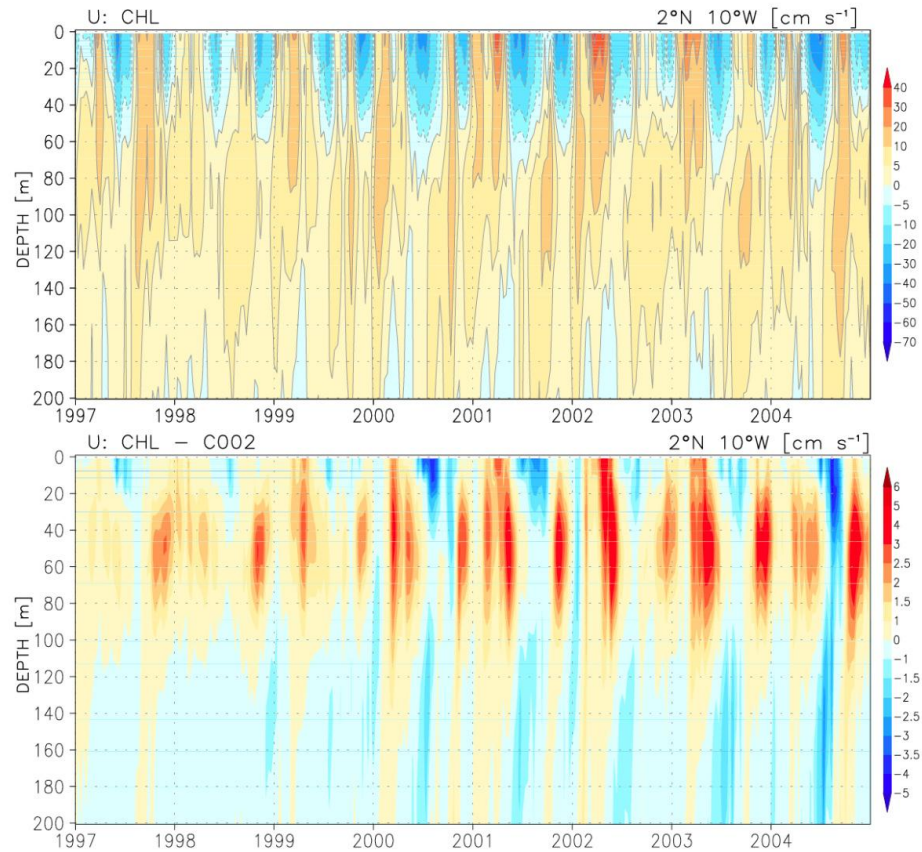

Figure 8b. Time series of zonal velocity profile at $2^{\circ} \mathrm{N}$ and $10^{\circ} \mathrm{W}$ : (Top) CHL run; (Bottom) Difference between CHL and $\mathrm{C002}$ runs. 

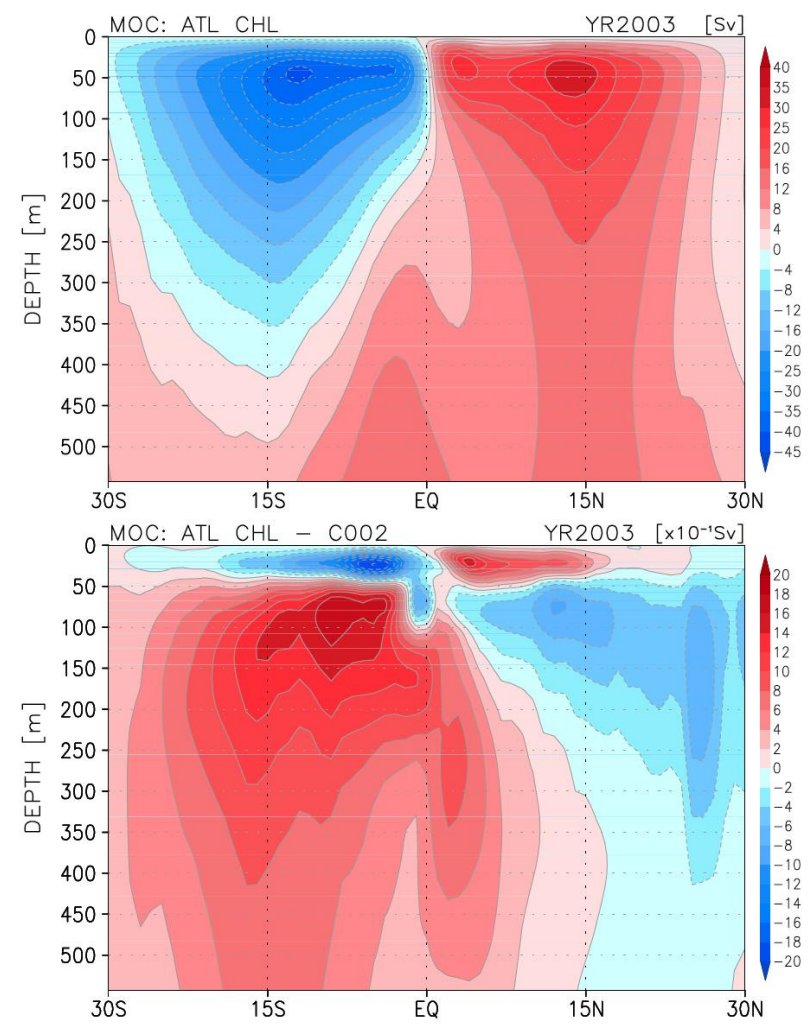

Figure 9. Meridional circulation of the Atlantic (year 2003): (Top) CHL run, and (Bottom) Difference between CHL and $\mathrm{C002}$ runs.

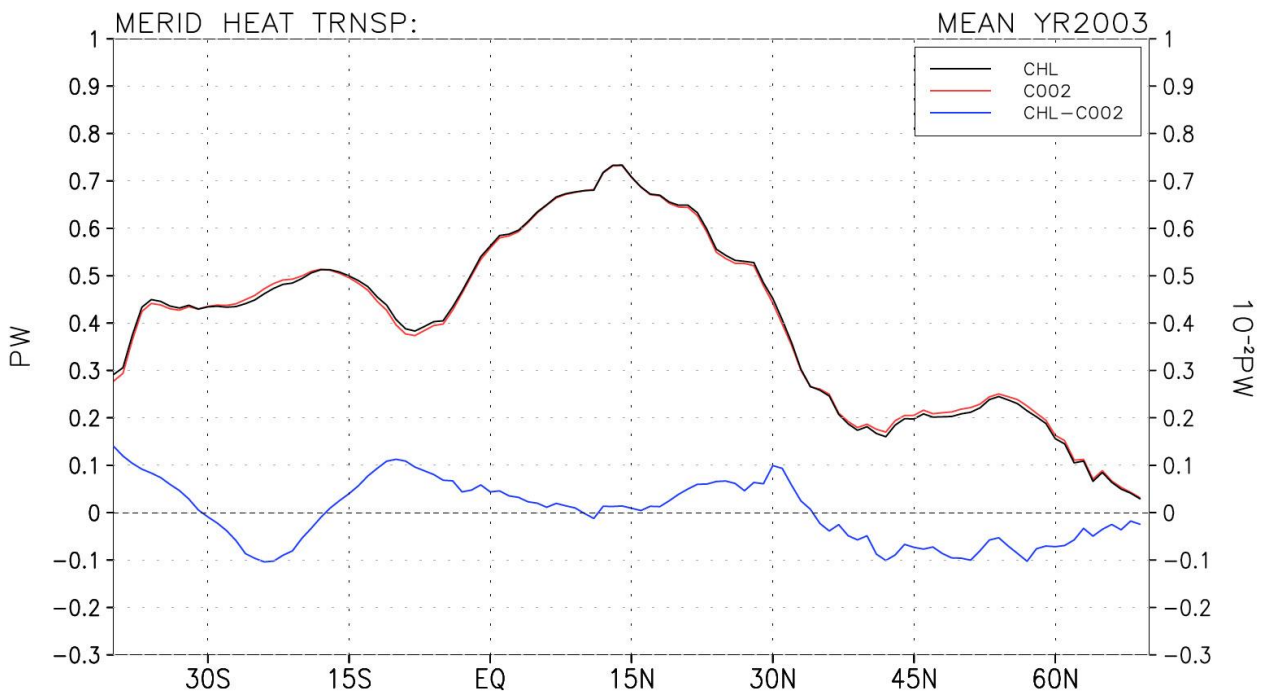

Figure 10. Annual meridional heat transport in the Atlantic in2003: (Black) CHL run, (Red) C002 run, and (Blue) Difference between CHL and C002 runs. Phytoplankton-radiation forcing tends to reduce the pole-ward heat transport north of $35^{\circ} \mathrm{N}$. 